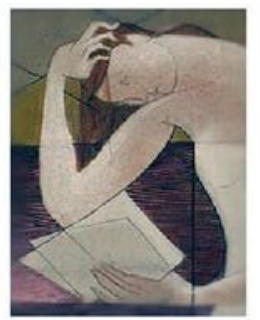

\title{
Oswald de Andrade e a antropofagia na crítica formativa de Antonio Candido
}

\section{Oswald de Andrade and the anthropophagy in the formative criticism of Antonio Candido}

\begin{abstract}
Resumo: Neste artigo, analisamos os ensaios de Antonio Candido sobre obra de Oswald de Andrade, especialmente "Estouro e libertação", de 1944, e "Digressão sentimental sobre Oswald de Andrade", de 1970, buscando elucidar os pressupostos da crítica formativa e os contrastes que estabelece com o discurso da antropofagia.
\end{abstract}

Palavras-chave: Antonio Candido; Oswald de Andrade; Antropofagia; Formação.

Abstract: In this article, we analyze Antonio Candido's essays on Oswald de Andrade's work, especially "Estouro e liberação", 1944, and "Sentimental digression about Oswald de Andrade", by 1970, seeking to elucidate the assumptions of formative criticism and the contrasts it establishes with the discourse of the anthropophagy.

Keywords: Antonio Candido; Oswald de Andrade; Anthropophagy; Formation.

\section{Oswald de Andrade na crítica de Antonio Candido: marcos iniciais}

Oswald de Andrade é o escritor brasileiro que melhor encarna o espírito modernista e o ímpeto da vanguarda. No entanto, passada a fase revolucionária do modernismo, que se estende da Semana de 1922 ao Manifesto Antropófago, de 1928, Oswald de Andrade sai do papel de "ponta de lança" do movimento para o quase completo ostracismo. A falta de reconhecimento da crítica é profundamente lamentada pelo escritor, que se ressente por suas ideias não terem tido o alcance e a repercussão que desejava.

Cabe a Antonio Candido, em 1944, a tarefa de fazer justiça à relevância da obra de Oswald de Andrade, através da publicação de um ensaio na Folha da Manhã, intitulado "Estouro e libertação", reunido posteriormente no livro Brigada ligeira, de 1945. Nesse

\footnotetext{
${ }^{1}$ Professora na área de Literatura Brasileira do Instituto de Letras da Universidade Federal do Rio Grande do Sul (graduação e Programa de Pós-Graduação).
} 


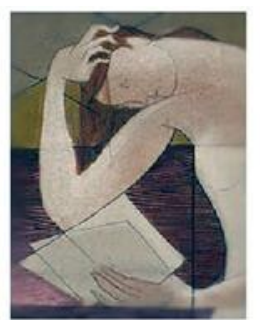

texto, estão presentes alguns aspectos metodológicos que constituem o que podemos chamar de "crítica formativa", cujos princípios Candido sistematizaria mais tarde no livro Formação da literatura brasileira, de 1959. De saída, podemos destacar o empenho de Candido em associar a produção contemporânea do autor (Oswald de Andrade havia lançado, em 1943, o primeiro volume de Marco Zero) àquela que o ligava ao movimento modernista de 1922, revelando um procedimento central à ideia de formação: o estabelecimento das diretrizes poéticas do autor a partir de uma visada histórica que assinala na obra elementos de continuidade e ruptura com a tradição.

Candido mergulha na especificidade da obra de Oswald de Andrade, combinando perspectiva histórica e análise crítica. Contudo, no caso do autor em foco, essa não é uma tarefa fácil, haja vista, como reconhece o crítico, que "Oswald de Andrade é um problema literário" (CANDIDO, 2004, p. 11). Essa situação, segundo Candido, deve-se à mitologia criada em torno do autor, ou seja, a sobreposição do personagem anárquico, irreverente e iconoclasta à sua própria obra, gerando uma deformação da figura do escritor pela opinião pública e uma decorrente incompreensão e descrédito de sua produção literária.

Não deixa de ser sintomático que a aproximação a Oswald de Andrade comece pela estranheza e desconforto diante de sua pessoa e obra, que não se encaixam na "normalidade" dos padrões sociais, culturais, intelectuais e estéticos daquele momento. O reconhecimento dessa posição deslocada de Oswald não impede, porém, que o crítico ceda à necessidade de estabelecer parâmetros estáveis e seguros de análise, que deem legitimidade ao grande escritor que nele reconhece. Candido pretende desfazer a visão deformada, simplista e pouco séria acerca de Oswald de Andrade, por meio de um esforço de análise "livre do fermento combativo característico de sua personalidade" (2004, p. 12), posto que a irreverência e o traço "temperamental" da personalidade do pensador da antropofagia são empecilhos que dificultam a compreensão da sua obra. Nesses termos, reivindicando o princípio da objetividade crítica, Candido explicita seu foco de análise:

Nele, só abordarei o romancista, deixando de lado os outros aspectos de um autor que é também poeta, jornalista, dramaturgo. Quanto à sua pessoa e à sua atividade modernista; quanto ao homem da Antropofagia e o bicho-papão do burguês aterrorizado, deixo-o para os biógrafos e possíveis autores de ABC. (2004, p. 12) 


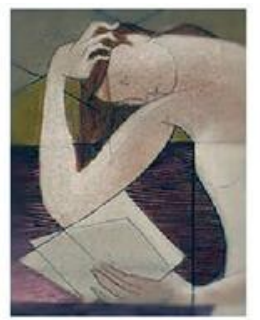

Ao se concentrar no romancista, Candido deliberadamente deixa de fora a figura de Oswald de Andrade como agente cultural e homem de ideias, o "homem da Antropofagia" - pois se tratava, naquele momento, de destacar a obra, que teria ficado em segundo plano, obscurecida pela presença marcante e ostensiva da personalidade. Além disso, outros pressupostos da sua crítica se evidenciam: - o destaque a um gênero (no caso, o romance); - o esforço de objetividade, buscando fundamentar o juízo na análise da obra, com notável trabalho de leitura; - a noção de crítica como um gênero que não se confunde com a crônica romanceada ou com a biografia. Isso tudo parece conduzir à justificação da "grandeza" do autor, mesmo que o crítico reconheça certas "falhas" na realização estética das obras. O critério de grandeza ou superioridade - que caracteriza um certo traço evolutivo no conceito de formação - consiste em notar um ponto alto na realização estética do autor, que se revela no projeto bem-sucedido de obras exemplares, capazes de configurar uma forma "universal" que incorpora as contradições das circunstâncias históricas "locais".

$\mathrm{Na}$ leitura de Candido, os romances de Oswald de Andrade passam pelo crivo de uma "evolução dinâmica e não raro contraditória, ao longo da qual, todavia, percebe-se um desenvolvimento coerente." (2004, p. 12), aspecto evidenciado na identificação de três momentos na produção de Oswald: o primeiro corresponderia à Trilogia do exílio (Os condenados, 1922; A estrela de absinto, 1927; A escada vermelha, 1934); o segundo consistiria no par Memórias sentimentais de João Miramar, de 1924, e Serafim Ponte Grande, de 1933; o terceiro seria composto pelo primeiro volume de Marco Zero, A revolução melancólica, de 1943 (Chão, o segundo volume, é publicado em 1945, depois da escrita do ensaio de Candido).

O critério usado para essa classificação não é a cronologia, pois as fases não são lineares, elas se sobrepõem uma à outra, sendo a última ainda inacabada. Candido reconhece em cada uma dessas etapas aspectos significativos, que tornam a produção de Oswald de Andrade "bem mais fácil de ser compreendida e interpretada" (2004, p. 13). Assim, o primeiro momento corresponderia à atitude católica e pós-parnasiana; o segundo diria respeito à sátira social, à revolta e à demolição de todos os valores (com melhor êxito de Miramar do que Serafim, que Candido considerava um romance com problemas de realização); o terceiro seria a síntese dessas duas linhas. 


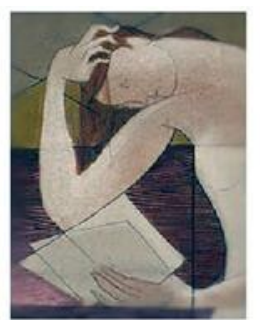

Não é preciso detalhar a análise que Candido faz de cada um dos romances; importa notar o esquema, ou a arquitetura de sua crítica, que revela o empenho de chegar a uma dialética integradora, a uma síntese de tendências contraditórias, que articulam passado e presente. Isso dá base a que Candido identifique sinais de êxito literário, mesmo não deixando de apontar fraquezas no projeto estético de Oswald, decorrentes de "corpos estranhos que ainda perturbam a síntese visada" (2004a, p. 26), como é particularmente o caso de A revolução melancólica. A despeito disso, ao final do ensaio, Candido faz uma aposta no desenvolvimento literário exitoso de Oswald de Andrade: Marco zero se tornará uma obra finalmente à altura do nome do seu autor, caso
esse consiga solucionar as sobrevivências da fase dannunziana, forjar um estilo
tão expressivo quanto o das Memórias sentimentais de João Miramar e
conseguir, finalmente, aprofundar a psicologia dos seus personagens. (2004, p.
26)

A "fórmula" do ideal estético requerido por Candido exige a superação de tendências ligadas a modelos do passado, no caso, a tradição da poesia italiana, representada pelo poeta Gabriele d'Annunzio (1863-1938). ${ }^{2}$ De outra parte, Candido ratifica a linha expressiva de vanguarda, aberta por Memórias sentimentais de João Miramar, que considera alcançar "um tom másculo de revolta, sátira, demolição, subversão de todos os valores (2004a, p. 13), mas acaba chamando atenção para possíveis fragilidades na construção psicológica dos personagens, critério afeito à linha dos grandes romances da tradição do século XIX, que tem Machado de Assis, no Brasil, o caso exemplar.

Vale a pena contrapormos as ressalvas de Candido aos comentários do próprio Oswald, que rebate o "professoral azedume", oferecendo outras perspectivas de interpretação. Oswald de Andrade recorre aos argumentos críticos de Roger Bastide também à época professor da USP -, que se situam na contramão da crítica de Candido, conforme lemos em texto compilado em Ponta de lança, livro que reúne conferências e artigos publicados por Oswald de Andrade entre 1943 e 1944 em jornais paulistas:

\footnotetext{
${ }^{2}$ Vale lembrar que o poeta italiano "assimilou as características principais do decadentismo europeu e da poesia crepuscular, como o gosto pelo tecnicismo formal e o primor de estilo", transformando-se em alvo dos futuristas, sobretudo Marinetti, que "satiriza a imagem de dandy de d'Annunzio". Disponível em Modernismo: Arquivo Virtual da Geração de Orpheu, https://modernismo.pt/index.php/g/592-gabriele-dannunzio . Acesso em 15/2/2020.
} 

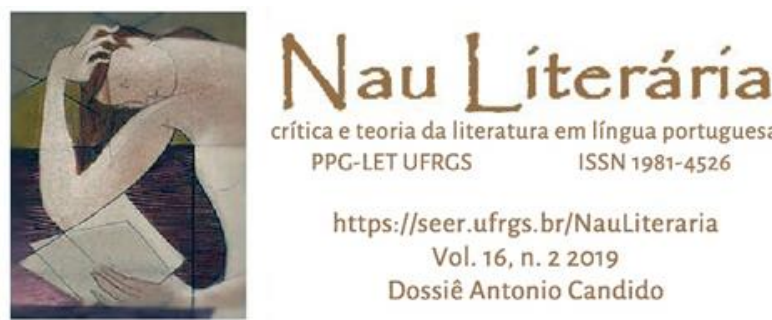

Foi com o sorriso fino que o Sr. Antônio Candido encerrou o seu artigo de domingo. "Mas não será isso uma questão de gerações?"... Traduzindo, quer ele dizer que a geração de 22 , que me deram de presente, "esquece frequentemente no entusiasmo do ataque, que o fundamento ético da crítica é a análise justificativa". Tomo com todo respeito esse período que é uma joia de fórum, e vou mostrar como a análise que acaba de fazer de minha obra o Sr. Antônio Cândido é, ao contrário, um modelo de leviandade carrancuda. Vou apenas por à frente do seu professoral azedume a crítica serena e minuciosa, refletida e ilustre, de outro professor, o Sr. Roger Bastide, sobre o meu primeiro livro. A autoridade que invoco, não é a do catedrático de Sociologia da Faculdade de Filosofia, de quem o Sr. Antonio Candido é o assistente. É a do crítico mesmo, o crítico interessado, culto e constante que produziu entre todos, aquele estudo magistral sobre a paisagem em Machado de Assis. Diz o Sr. Antônio Candido: "Feliz como solução técnica, Os Condenados são um romance falho como criação de personagens, como expressão de humanidade." Afirma o Prof. Roger Bastide: "Nesse sentido (do sentimento amoroso brasileiro) Os Condenados ocupariam no Brasil uma posição análoga à que ocupa na França Madame Bovary. É o fim de uma certa concepção do amor, é o ponto final de uma época que começou com Machado de Assis. Machado é a introdução do amor romântico no interior da família burguesa; Oswald é a decomposição desse romantismo amoroso." O Sr. Antônio Cândido, multiplicando toda a sua argúcia cultivada no convívio universitário, não viu nada disso (ANDRADE, 1991, p. 67).

$\mathrm{Na}$ continuidade do artigo, Oswald de Andrade desfila uma série de comentários de escritores e críticos, tais como Carlos Drummond de Andrade, Monteiro Lobato, Afrânio Peixoto, Astrogildo Pereira, entre outros, que apontam as qualidades inovadoras da obra e o "lugar definitivo" do autor da Poesia Pau-Brasil na história das letras nacionais. Para além da busca por reconhecimento e do referendo como renovador da tradição literária, há na atitude de Oswald de Andrade algo mais do que simples polêmica ou ressentimento. A combatividade e o entusiasmo da geração de 22, que Candido faz questão de afastar da obra de Oswald, tem para este papel decisivo, daí considerar o período "uma joia de fórum", tomando-o "com todo respeito". Assim, o que para Candido seria um "problema literário", para Oswald de Andrade é uma tomada de posição estética das mais relevantes.

Oswald é consciente do seu papel de "ponta de lança" da vanguarda modernista, mostrando que nunca deixou de falar como o "homem da antropofagia". Naquele contexto dos anos 1940, reafirmar as posições combativas de 22 juntava-se à resistência antifascista, que Oswald considerava necessário "para que saibamos ocupar nosso lugar na história contemporânea" (OSWALD, 1991, p. 116). O momento não dava lugar para "neutros ou anfíbios" (id., ib.). Oswald expõe sua insatisfação com os regimes 


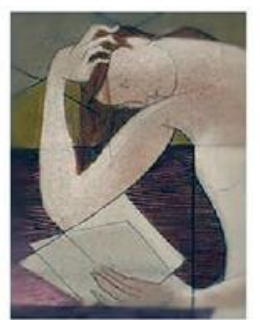

autoritários, cerceadores da liberdade de criação e da utopia de um mundo redimido, onde a humanidade possa comer "à mesma mesa, com a mesma fome justa satisfeita, sob o mesmo tendal de fraternidade e de democracia" (1991, p. 118).

De certa forma, o banquete antropofágico assume nesse contexto contornos abertamente políticos, indicando que não é possível isolar a produção artística da práxis vital, que se manifesta nas relações literárias assumidas pelo artista. Assim, aquilo que, aos olhos do crítico "severo", é visto como "problema literário" (o "fermento combativo característico da sua personalidade"), fruto da leviandade de uma geração, para Oswald, ao contrário, é o preço a ser pago por "ter caminhado decididamente para o futuro" (1991, p. 112). A crítica de Candido está centrada na análise do plano formal ${ }^{3}$, apostando que os elementos expressivos irresolvidos na obra oswaldiana (os "corpos estranhos") encontrarão, em produções vindouras, melhor realização e destino (a "síntese visada"). Contudo, na concepção oswaldiana, o futuro não é um resultado esperado, nos termos de uma síntese dialética de ordem formal, posto que a história não é linear, mas marcada por rupturas que tensionam e desviam os modos como as próprias relações literárias são concebidas no seio das instituições burguesas, tema central no movimento das vanguardas históricas.

Sem considerarmos os questionamentos trazidos pelas vanguardas ao estatuto burguês da arte, não é possível dimensionarmos adequadamente a atuação de Oswald de Andrade no campo literário brasileiro. Antes de qualquer coisa, como aponta Peter Burger (1993), os movimentos de vanguarda são uma crítica à própria arte como instituição, deslegitimando as categorias essenciais ainda vigentes na definição da arte, tais como a organicidade e a subordinação das partes ao todo. Não se trata da simples renovação de processos literários, mas da ruptura de uma tradição: “os movimentos históricos de vanguarda não só pretendem romper com os sistemas de representação herdados, como ainda aspiram a superar a instituição arte em geral" (BURGER, 1993, p. 110). Não apenas as ideias dominantes de arte sofrem uma transformação, como todo o mecanismo de produção, distribuição e recepção. Ou seja, a vanguarda dirige-se contra as formas de

\footnotetext{
${ }^{3}$ Candido irá desenvolver em ensaios posteriores a sua concepção de forma literária como síntese da matéria histórica. Sua proposta de crítica dialética entende que o elemento externo, social, é parte da estrutura literária. O papel da crítica, nesses termos é o de perceber e avaliar a organicidade da obra, que demanda uma "interpretação dialeticamente íntegra", capaz de fundir texto e contexto.
} 


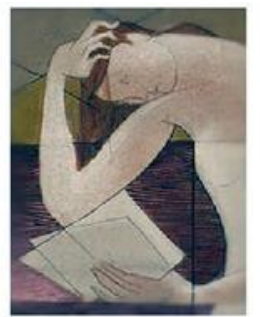

submissão da arte ao controle exercido pelo status da sociedade burguesa. Mesmo que as vanguardas não tenham destruído a instituição arte - afinal, sua provocação se dá na esfera burguesa e sua capacidade de protesto é rapidamente absorvida pelo mercado -, "talvez tenham acabado como a possibilidade de uma determinada tendência artística poder apresentar-se com a pretensão de validade geral” (id., p. 148). Assim, é a própria validade das normas estéticas que passa a ser questionada.

Esse espírito de ruptura dos princípios estéticos da arte é encarnado na atuação de Oswald de Andrade, em todos os âmbitos de sua produção, seja na poesia, no romance, no teatro, nos manifestos, nos ensaios filosóficos, nas crônicas, nos artigos jornalísticos e nas polêmicas que marcam a sua trajetória de veementes convicções e também, como afirma Mario da Silva Brito, na "coragem de se desdizer, de retratar-se, de dialeticamente contradizer-se, de rever-se a si mesmo, corrigindo enganos, equívocos e às vezes irritada visão de pessoas, fatos e circunstâncias" (1974, p. 18). O alegado "caráter personalista" que Oswald "assume nas suas relações literárias" (CANDIDO, 2004, p. 12) pode ser visto como parte da intenção, típica da vanguarda, de "superação da arte enquanto ordem separada da práxis vital” (BURGER, 1993, p. 95). Assim, a análise da atuação artística oswaldiana, movida pelo espírito da vanguarda, implica levar em conta não só a ruptura com as formas artísticas da tradição, mas também a crítica ao lugar social do escritor e à própria arte como instituição. A produção de Oswald de Andrade e o seu papel de intelectual passam pelo influxo das vanguardas históricas, o que requer que se leve adiante o questionamento da autonomia do literário, pois o significado e o efeito social da obra não se dissociam da atuação do artista e das instituições onde tudo funciona. Esse parece ser o verdadeiro "problema literário" de Oswald de Andrade: a recusa da arte como instituição burguesa e os limitados efeitos políticos desse projeto, determinados pela própria instituição arte, que ainda constitui na sociedade burguesa um âmbito separado da práxis vital" (BURGER, 1993, p. 153-154).

\section{A revisão crítica de Antonio Candido}

A visão crítica inicial de Candido alimentava-se, como vimos, da expectativa de que o melhor do autor estaria por vir - uma espécie de promessa, a ser cumprida em 


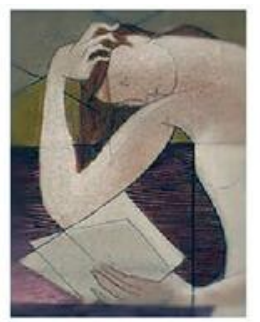

patamar superior no futuro. No ensaio "Digressão sentimental sobre Oswald de Andrade", de 1970, Antonio Candido reconhece, com notável sinceridade, os limites do juízo crítico de 1944, que sofria, segundo ele, da "obsessão com expectativa e justificação”.

Candido reverte o seu juízo em relação a Serafim Ponte Grande, reconhecendo nele um "grande romance", posto ao lado de Memórias sentimentais de João Miramar. A "falha" do primeiro ensaio estaria justamente em não reconhecer que o melhor já se mostrava nesses dois romances e tudo o que viesse depois "viria por acréscimo" (2004b, p. 36). O gesto crítico, contudo, está orientado pelo mesmo princípio, pois insiste em localizar na produção do autor um momento de realização e culminância, reiterando um procedimento que parece típico do pensamento da formação, que pretende fixar em certas obras o ponto máximo de estabilização de um paradigma estético.

Novamente, nesse ensaio, Candido emprega uma metodologia semelhante de leitura, interpretando a obra de Oswald a partir da divisão em três grupos de romances, tal como havia estabelecido no primeiro texto crítico. Ressalta, porém, com mais ênfase, o momento de excelência de Miramar-Serafim, obras em que o escritor obtém a síntese ótima entre sarcasmo e poesia, experiência pessoal e humorismo (CANDIDO, 2004b).

Se, no primeiro ensaio, Candido atribuiu a cada uma das fases uma característica definidora, neste segundo, a sua síntese dialética busca apreender o conjunto dos romances das três fases a partir de uma plataforma expressiva comum, ou seja, a partir de características estruturadoras, generalizáveis, com diferentes modulações. Esses traços comuns, que funcionam como chave de compreensão do conjunto da obra, são definidos a partir de dois conceitos: devoração e mobilidade. (2004b, p. 49).

$\mathrm{Na}$ avaliação de Candido, porém, essas chaves de leitura não funcionam bem em todos os romances. Em alguns casos, conduzem mesmo a uma apreciação negativa, à constatação de uma realização estética insuficiente, uma falta de perícia em harmonizar os conflitos entre "técnicas" e "panorama social". Miramar e Serafim são os romances que levam “a devoração e a motilidade ao grau máximo", sendo o ponto alto da realização estética de Oswald de Andrade.

Candido pouco fala da antropofagia, mas nota, em Serafim, a transposição do primitivismo antropofágico para a escala da cultura burguesa, como uma espécie de Macunaíma urbano (2004b, p. 58). O crítico não chega a desenvolver a análise do que 


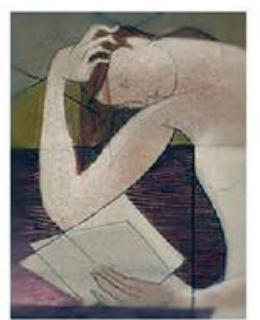

seria essa qualidade antropofágica de Serafim, talvez por não reconhecer nessa temática uma formulação acabada:

É difícil dizer no que consiste exatamente a antropofagia, que Oswald nunca formulou, embora tenha deixado elementos suficientes para vermos embaixo dos aforismos alguns princípios virtuais, que a integram numa linha constante da literatura brasileira desde a Colônia: a descrição do choque de culturas, sistematizada pela primeira vez nos poemas de Basílio da Gama e Santa Rita Durão. (2004b, p. 58)

A necessidade de apreender o conceito de antropofagia - que, para Candido, "Oswald nunca formulou" (afirmação questionável, se considerarmos os inúmeros textos de Oswald sobre o tema) -, leva o crítico a sintetizar o aspecto básico do encontro cultural, através da exploração do primitivismo. Na interpretação da antropofagia feita por Candido, persiste um movimento próprio do pensamento da formação, caracterizado por uma visão sistêmica, que vincula a obra a tradições anteriores, levadas adiante e renovadas. Assim, notemos que o primitivismo da antropofagia é localizado inicialmente nos poemas de Basílio da Gama e Santa Rita Durão, que, pela primeira vez, poriam em destaque o encontro cultural. Candido não desenvolve, neste ensaio, o modo como a antropofagia estaria presente no tema do encontro cultural representado na épica dos poetas árcades. Todavia, se buscarmos em Formação da Literatura Brasileira (1997) o que diz Candido sobre Basílio da Gama e Santa Rita Durão, verificamos que o crítico ressalta a oposição entre rusticidade e civilização; ordenação racional da Europa e primitivismo do índio; consciência do desajuste cultural e sentimento de diferenças culturais (CANDIDO, 1997). No embate cultural, conforme sugere Candido, os poemas acabam revelando, a despeito da simpatia pelos indígenas, a inadequação do primitivo face à empresa civilizatória.

O crítico assinala que o Modernismo, por sua vez, dá outro cunho à antropofagia, a exemplo de Macunaíma e Serafim Ponte Grande, acentuando o choque entre o primitivo e o urbano; o natural e o civilizado; cultura indígena e cultura burguesa; o local e o cosmopolita. Candido sugere ainda que o primitivismo é levado a cabo de maneiras diferentes na viagem de Macunaíma do Amazonas a São Paulo, em que o primitivo amazônico é revisto em escala urbana; e na viagem de Serafim de São Paulo à Europa, que o confronta com a dimensão cosmopolita e fascinante do velho Continente, ante o 


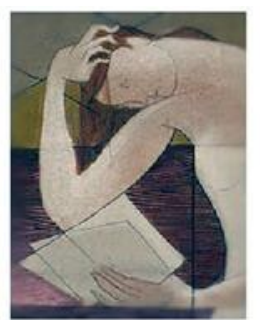

qual seríamos primitivos. A síntese devoradora, conforme assinala, contém um elemento de agressividade que desmancha a linha burguesa do decoro e da medida, produzindo um choque que quebra o equilíbrio, "por meio de certas formas do excesso, como o grotesco, o erótico e o obsceno, que apareciam de maneira recalcada em nossa literatura, useira noutros excessos: o sentimental, o patético, o grandiloquente" (CANDIDO, 2004b, p. 59).

Antonio Candido entende a antropofagia como um meio de absorver o material da cultura dominante (externa ao país) e torná-la elemento próprio, incorporado à realidade local e subjetiva, tão bem encarnada por Oswald de Andrade: "Devoração é não apenas um pressuposto simbólico da Antropofagia, mas o seu modo pessoal de ser, a sua capacidade surpreendente de absorver o mundo e triturá-lo para recompô-lo" (id., ib., p. 49). Candido nota, no discurso de Oswald, a "moagem de pessoas, fatos e valores"; "uma utilização desmesurada de tudo, para chegar a um conhecimento, uma noção, ao menos um aumento de informação, como se quisesse deglutir o mundo" (id., ib., p. 49). Na crítica de Candido, a antropofagia é um recurso literário capaz de explicitar e articular as contradições entre o civilizado e o primitivo, formulação que parece estar no cerne do discurso da formação, o que merece ser examinado.

\section{Antropofagia e formação: contrapontos críticos}

A partir da interpretação de Candido sobre a antropofagia, podemos indagar de que forma o crítico apropria-se do conceito oswaldiano, fazendo-o nos termos do discurso da formação. Ou, em outras palavras, refletirmos sobre o que marca a diferença entre o discurso da antropofagia e o discurso da formação como métodos críticos. Não vamos proceder aqui a um desenvolvimento aprofundado do conceito de formação, tarefa realizada por inúmeros e reconhecidos estudiosos, em publicações que revisam criticamente a obra de Antonio Candido ${ }^{4}$. Cumpre-nos apenas retomar o conceito nos termos formulados pelo autor, destacando aqueles aspectos que contrastam com ao discurso da antropofagia.

\footnotetext{
${ }^{4}$ A exemplo da publicação $O$ Brasil ainda se pensa: 50 anos de Formação da Literatura Brasileira (2012), sem deixar de mencionar as análises de Roberto Schwarcz sobre a obra de Candido, especialmente em Sequências brasileiras (1999).
} 

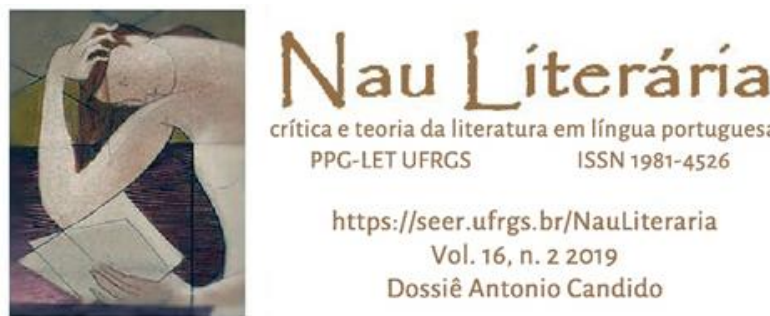

O conceito de formação é esboçado no primeiro volume de Formação da Literatura Brasileira, como preâmbulo do esquema crítico-metodológico que orienta a concepção historiográfica no estudo da literatura. A ideia de formação, em Candido, está ligada às noções de tradição e sistema; uma formação, portanto, diz respeito à constituição de um sistema orgânico de produtores literários, reconhecidos como criadores de obras que encontram circulação social e alimentam o consumo dos leitores. A continuidade ininterrupta desse processo assegura a tradição, sem a qual "não há literatura, como fenômeno de civilização (CANDIDO, 1997, p. 24).

A existência de um sistema articulado de autores, obras e leitores garante as condições mínimas de existência do sistema literário, articulado ao sistema da civilização. A literatura só pode alcançar a universalidade e o caráter de patrimônio cultural da civilização se integrada a um sistema cujos valores legitimam a tradição na qual ela se integra. Nesta perspectiva, percebe-se, na descrição do processo formativo, um movimento linear, iniciado com os poetas mineiros árcades - que plantaram "de vez a literatura do Ocidente no Brasil, graças aos padrões universais por que se regia, e que permitiram articular a nossa atividade literária com o sistema expressivo da civilização a que pertencemos, e dentro da qual fomos definindo lentamente a nossa originalidade" (CANDIDO, 1997, p. 17). O processo formativo culmina com o Romantismo, no século XIX, quando são criadas as condições para o surgimento de uma tradição, com autores e obras que passam a circular e a comunicar-se entre si.

O esquema interpretativo de Candido permite ver o processo de formação do sistema literário como substrato de análise da formação social brasileira nos seus aspectos condicionantes e conflitivos, ligados à situação de dependência da metrópole e ao desejo de afirmação da identidade nacional. O eixo que atravessa a análise do processo formativo da literatura e da sociedade brasileiras é a dialética entre o local e o universal, tomando os padrões civilizatórios europeus como universais, o que, de certa forma, sela o destino de dependência do país e confere à literatura brasileira uma espécie de missão ou a intenção "de estar fazendo um pouco da nação ao fazer literatura" (CANDIDO, 1997, p. $18)$.

Esse rápido esboço do "esquema da formação" é suficiente para explicitar que a antropofagia oferece uma interpretação a contrapelo, pois não tem na civilização o seu 


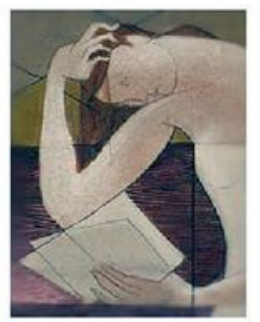

fundamento, relativizando o argumento da dependência, ligada ao elemento primitivo, justamente o que precisa ser superado, de acordo com a dialética formativa. Nesse enquadramento, a antropofagia é mais do que uma vanguarda estética, é uma categoria de análise cultural, que ganha corpo no pensamento oswaldiano, para além do Manifesto Antropófago. O tema acompanhou as reflexões de Oswald de Andrade até o final de sua vida, ganhando contornos filosóficos que confrontam os sistemas de representação da sociedade capitalista ocidental. No ensaio A crise da filosofia messiânica, de 1950, Oswald de Andrade elabora filosoficamente o conceito de antropofagia, ampliando-o para uma leitura política da história da civilização e explicitando sua crítica à violência estrutural do processo civilizador da cultura ocidental. A antropofagia aparece, assim, como dispositivo de pensamento, uma matriz de inteligibilidade, que tem por base uma epistemologia primitiva.

Para uma compreensão mais adequada da antropofagia oswaldiana, é necessário entender minimamente como funciona a antropofagia literal, as funções do rito antropofágico nas sociedades primitivas. O senso comum generalizado de que o antropófago come o inimigo para absorver dele as qualidades positivas, como a força e a coragem, pressupõe uma espécie de suplantação do outro, em proveito e vantagem própria, que não condiz com a antropofagia ritual. Entendido assim, fora do significado da devoração na cosmologia indígena, é todo um universo de sentido que se perde, correndo o risco de ser interpretado segundo uma visão etnocêntrica, que submete o outro aos valores e referências de quem interpreta. Apreender o sentido literal da antropofagia importa para conservar a dimensão cultural do conceito, evitando diluí-lo numa simples categoria estética que relaciona modelos artísticos europeus e arte nacional ${ }^{5}$.

$\mathrm{O}$ contato cultural pressuposto na antropofagia tem o sinal invertido no pensamento de Oswald de Andrade, pois não pressupõe a relação de uma cultura dominante civilizada sobre uma cultura dominada selvagem. No Manifesto Antropófago, Oswald de Andrade subverte esse esquema interpretativo, fazendo pensar, inversamente, na maneira como a cultura europeia, colonizadora, é transformada na medida em que se

\footnotetext{
${ }^{5}$ Para uma análise pormenorizada sobre o ritual da antropofagia, remetemos ao artigo do antropólogo Carlos Fausto , intitulado "Cinco séculos de carne de vaca: Antropofagia literal e Antropofagia literária". In: RFFINELLI, J.; CASTRO ROCHA, J. Cezar (org.), 2011.
} 


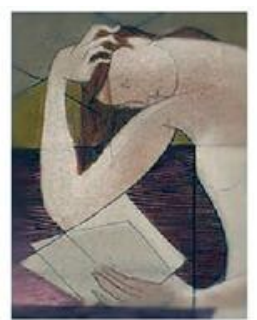

impõe a outros povos e culturas.

Queremos a Revolução Caraíba. Maior que a Revolução Francesa. A unificação de todas as revoltas eficazes na direção do homem. Sem nós a Europa não teria sequer a sua pobre declaração dos direitos do homem. (1990, p. 48)

A inversão do ponto de vista já está posta no conhecido poema "Erro de português", publicado em Primeiro caderno de poesia do aluno Oswald de Andrade, de 1927, no qual a descoberta do Brasil é contada sob a hipótese de uma inversão da história:

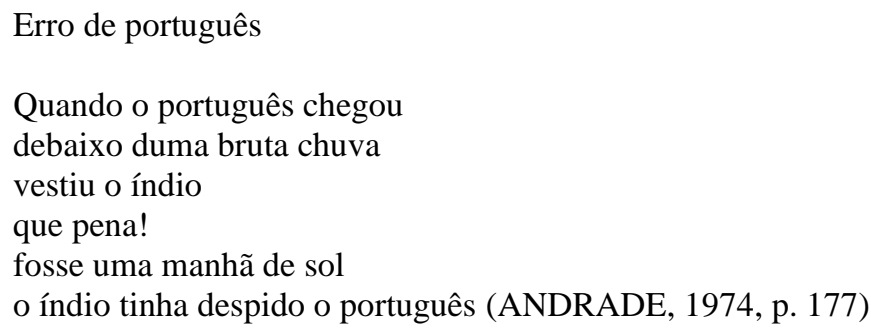

Na visão de Oswald, sem o contato com as culturas dos outros povos não se produziriam, no chamado Velho Mundo, as transformações culturais que teriam levado ao Iluminismo, à Revolução Francesa, à Declaração dos Direitos do Homem e à modernidade (como teriam aparecido Montaigne e Rousseau, por exemplo?). Na visão oswaldiana, o contato com os ditos "selvagens" da América passava a produzir uma mudança na "consciência europeia", colocando em questão a universalidade da tradição que os europeus conheciam até então.

Essa inversão de perspectiva é plena de consequências, pois desbanca alguns dos valores sagrados da civilização burguesa capitalista. As ideias vitais de propriedade, liberdade e justiça necessariamente são postas em xeque face às culturas ameríndias. Em lugar de reduzir espontaneamente as diferenças a um arquétipo universal, Oswald focaliza os fatos e as experiências das culturas locais como modelo, percebendo no processo colonizador a dívida da cultura moderna para com os povos conquistados - lição a ser ainda aprendida, em termos sociais, econômicos e epistemológicos. Podemos, assim, perguntar, a partir de Oswald: o que o pensamento e a arte moderna europeia devem, na sua própria formulação e nos seus próprios códigos (ou seja, conceitualmente), aos povos que colonizou? Nesses termos, a antropofagia funciona como diferença em relação ao 

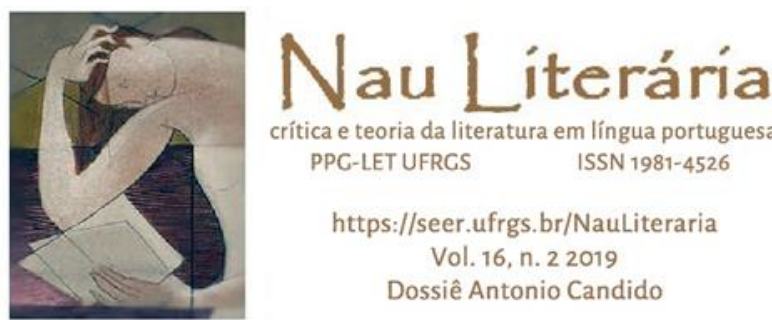

discurso da formação, como desenvolve o estudo de Raphael Meciano (2018), subvertendo a relação de dependência, pois

\begin{abstract}
não se trata de entender como determinadas "formas", ideias, ou uma certa linguagem, primordialmente europeia, universalizou-se produzindo variantes nacionais ocidentais e com características locais singulares (porém integradas ao universal[izado] código ocidental). Mas sim, e por outro lado, com Oswald, cumpriria perguntar: o que há no código ocidental (que teria se universalizado por meio da colonização) de pressupostos dos povos conquistados? O que, afinal de contas, sempre esteve "fora" do ocidente? (2018, p. 103).
\end{abstract}

O pensamento da antropofagia não coincide com o esforço de construir a nação, em moldes europeus, pois a descolonização suscita uma crítica ao modelo de sustentação do estado nacional civilizado ocidental, ou seja, a integração à modernidade global necessariamente inclui a perspectiva da cultura primitiva. Desfaz-se, assim, a oposição entre nação civilizada/dominante/estrangeira $\mathrm{X}$ nação dependente/colonizada/ nacional. O imperativo da nacionalidade, fundamental no discurso da formação, perde a relevância no pensamento antropófago, que não opera segundo a contraposição entre o nacional e o estrangeiro, e sim entre o patriarcado e o matriarcado, conforme propõe Oswald de Andrade em "Crise da filosofia messiânica" (1991).

O patriarcado representa os valores e as estruturas que moldam a civilização ocidental, baseada no direito paterno, na sociedade dividida em classes e na propriedade privada. O modelo matriarcal refere-se ao mundo primitivo, em que a sociedade não se divide em classes, o direito é materno e a propriedade é comum. A cultura antropofágica opera a síntese dialética entre o homem natural e o homem civilizado, resultando no "bárbaro tecnizado", uma espécie de híbrido, que não supõe a negação de nenhum termo da equação, antes ressaltando a diferença. A descolonização proposta pela antropofagia ocorre mediante a valorização das culturas primitivas, e não segundo a tradição europeia dos estados nacionais. As formas de organização das sociedades primitivas são desconhecidas dos povos brancos e precisariam ser levadas a sério na construção de um outro modelo de humanidade, como lemos no ensaio "Ainda o Matriarcado":

Nem exogamia nem o parentesco nem o totemismo foram abordados pelos homens privilegiados que palmilharam a nossa terra índia, ainda virgem nessa hora. Só depois da criação das universidades é que se começa a compreender aqui quanto haveria de útil e precioso nesse primeiro contato com o primitivo. (1990, p. 216) 


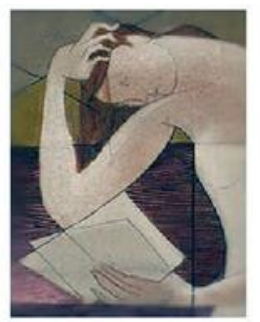

O primitivo é justamente o mundo que a civilização impede de existir, por conta da violência e barbárie com que se impõe. Nesse sentido, é verdade que "Oswald enfatiza uma força primitiva de resistência à doutrinação promovida pelo colonizador" (COSTA LIMA, 1991, p. 21), fazendo com que as características locais sejam interpretadas como exóticas e desajustadas aos códigos universais da modernidade burguesa. A despeito de Oswald de Andrade ser herdeiro dessa tradição - afinal, suas referências são, em grande parte europeias ${ }^{6}$-, isso não invalida a potência crítica do discurso da antropofagia, antes problematiza a posição do artista numa sociedade de classes e o lugar de hegemonia ocupado pela literatura.

A antropofagia aponta os limites históricos do processo civilizatório, lançando questionamentos aos valores da civilização como crivo de interpretação da história, aspecto bem percebido por Oswald de Andrade, quando afirma: "Todas as nossas reformas, todas as nossas reações costumam ser dentro do bonde da civilização importada. Precisamos saltar do bonde, precisamos queimar o bonde" (1990b, p. 41).

"Queimar o bonde" ou os navios da civilização é fundar outras bases para a cultura e a literatura, abrir-se a outras formas de pensar a história. Assim, na perspectiva de hoje, não é mais possível assumir a antropofagia nos moldes de uma insurgência respaldada apenas por modelos europeus, no esforço de deduzir a universalidade e pertencimento da literatura brasileira à civilização ocidental europeia. Oswald de Andrade talvez seja, se levada às últimas consequências sua dialética antropofágica, o caso mais exemplar de devoração da dialética formativa. Contudo, é graças à intuição do "problema literário" fixado na crítica de Antonio Candido que podemos "salvar" o gesto inconformista de Oswald, se o interpretarmos como resistência a certo modo de ler a tradição literária a partir de padrões estéticos ditos universais, à custa da exclusão de culturas e imaginários primitivos, que não se conformam à simples designação de características

\footnotetext{
${ }^{6}$ Para Evando Nascimento, o discurso da antropofagia traz uma contradição de base, pois "o antropófago de Oswald é totalmente 'civilizado', ou seja, ele é extraído das inúmeras leituras que o intelectual modernista fez de textos europeus" (2006, p. 158). Trata-se, de fato, de uma aporia, mas, ao contrário de invalidar a crítica oswaldiana à civilização, torna mais potente a necessidade de pensar em novos termos o processo civilizatório e sua relação com o primitivo.
} 


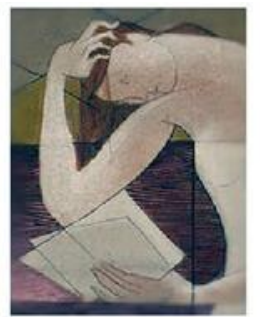

locais/nacionais, mas existem integrados ao patrimônio da civilização, exigindo seu lugar na história.

\section{Referências}

ANDRADE, Oswald de. Manifesto Antropófago. In: A utopia antropofágica. São Paulo: Globo, 1990a.

ANDRADE, Oswald de. Crise da filosofia messiânica. In: . A utopia antropofágica. São Paulo: Globo, 1990a.

ANDRADE, Oswald de. Ainda o Matriarcado. In: . A utopia antropofágica. São Paulo: Globo, 1990a.

ANDRADE, Oswald de. Contra os emboabas. In: . Os dentes do dragão: entrevistas. São Paulo: Globo, 1990b.

ANDRADE, Oswald de. Ponta de lança. São Paulo: Globo, 1991, p. 116

ANDRADE, Oswald de. Marco Zero I: a revolução melancólica. Rio de Janeiro: Civilização Brasileira, 1978.

ANDRADE, Oswald de. Marco Zero II: chão. Rio de Janeiro: Civilização Brasileira, 1978.

ANDRADE, Oswald de. Poesias reunidas. Rio de Janeiro, Civilização Brasileira, 1974 (Obras completas, v. VII).

BRITO, Mario da Silva. Conversa vai, conversa vem. Rio de Janeiro: Civilização Brasileira, 1974.

BÜRGER, Peter. Teoria da vanguarda. Tradução de Ernesto Sampaio. Lisboa, Vega, 1993.

CANDIDO, Antonio. Estouro e libertação. In: . Brigada ligeira. Rio de Janeiro: Ouro sobre Azul, 2004a.

CANDIDO, Antonio. Digressão sentimental sobre Oswald de Andrade. In: Vários escritos. Rio de Janeiro: Ouro sobre Azul; São Paulo: Duas Cidades, 2004b.

CANDIDO, Antonio. Formação da literatura brasileira. Belo Horizonte, Rio de Janeiro: Itatiaia, 1997.

CORRÊA, Ana Laura dos Reis; PILATI, Alexandre; CASTRO E COSTAS, Deane Maria Fonseca d ; BASTOS, Hermenegildo. O Brasil ainda se pensa: 50 anos de Formação da Literatura Brasileira. Vinhedo, SP: Editora Horizonte, 2012.

COSTA LIMA, Luiz. Antropofagia e controle do imaginário. In: Pensando nos Trópicos. Rio de Janeiro, Rocco, 1991, p. 21.

FAUSTO, Carlos. Cinco séculos de carne de vaca: Antropofagia literal e Antropofagia literária". In: RUFFINELLI, J.; CASTRO ROCHA, J. Cezar (org.). Antropofagia hoje? Oswald de Andrade em cena. São Paulo: Realizações Editora, 2011. 


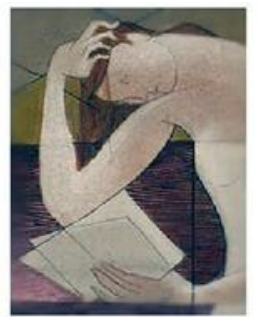

MECIANO, RAPHAEL. Formação e Diferença: o problema da relação entre os discursos de formação nacional e a antropofagia na crítica brasileira. Tese (Tese em História Social) - Universidade de São Paulo, USP. São Paulo. 2018.

NASCIMENTO, Evando. A desconstrução "no Brasil": uma questão antropofágica?. In: SANTOS, Alcides Cardoso. DURÃO, Fabio Akcelrud. SILVA, Maria das Graças G. Villa da. (org). Desconstrução e contextos nacionais. Rio de Janeiro: 7Letras, 2006.

SCWARCZ, Roberto. Sequências brasileiras. São Paulo: Companhia das Letras, 1999. 